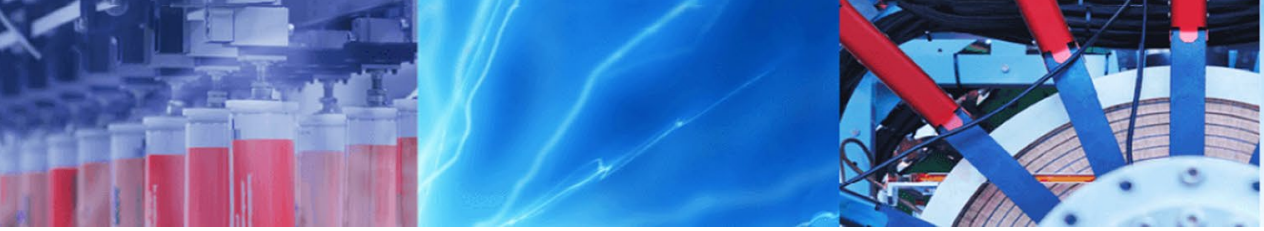

Research Article

\title{
Research on failure characteristics of goaf floor in the inclined coal seam based on the fracture mechanics
}

\author{
Jiazhen $\mathrm{Li}^{1}$ (1) $\cdot{\text { Zhengyi } \mathrm{Ti}^{1} \cdot \text { Feng Zhang }}^{1} \cdot$ Jiangtao Hu$^{1} \cdot \mathrm{Zhijie} \mathrm{Zhu}^{1}$
}

Received: 26 December 2019 / Accepted: 10 November 2020 / Published online: 24 November 2020

(c) Springer Nature Switzerland AG 2020

\begin{abstract}
Floor failure is the leading cause of mine water inrush after coal mining above the confined aquifer. Therefore, the prediction of floor failure depth is an important content of mine water prevention. The mining-induced failure depth and goaf floor characteristics are researched to grasp the goaf failure condition after the inclined coal seam mining with the theoretical analysis method. The inclined coal goaf floor's stress solving mechanics mode is set up based on the fracture mechanics theories. According to the Mohr-Coulomb criterion, the floor failure depth solving the equation is derived. With the theoretical analysis of the floor failure characteristics during the inclined coal seam mining, (1) the maximum failure depth of floor is nonlinear to the coal seam dip and the lateral pressure coefficient; the working face length, mining depth and floor cohesion positively correlate with the failure range; the floor cohesion is reversely proportional to the failure range. (2) There appears asymmetry in the layout of stress and plastic zones in the inclined coal goaf floor. Failure range and depth in-floor plastic zone increasingly enlarge when the coal face advances.
\end{abstract}

Keywords Fracture mechanics · Mohr-coulomb criterion · Inclined coal seam · Theoretical analysis method · Floor failure depth

\section{Introduction}

After the coal seam is mined, the rock strata stress in the goaf floor is redistributed. With the mining process, the stress successively goes through three stages of increase, decrease, and recovery, leading to the floor's deformation and failure, and finally forming a certain depth of rock strata failure zone, which seriously affects the coal mine production. Therefore, to realize the coal mine's safe and efficient production, it is of great practical significance to study the coal seam floor's failure characteristics.

In terms of theoretical calculation of goaf floor failure depth, Zhu et al. applied semi-infinite body theory of elastic mechanics, considering the effect supporting pressure exerts on the floor, and then established a mechanical model of coal floor [1-4]. Lu et al. treated limit equilibrium failure form of the floor under the supporting pressure as circular slip, applying the slip-line field's applied theory to calculate the maximum floor failure depth [5-10]. Zhang et al. comprehensively analyzed the influential factors from floor failure, modified empirical formula for floor failure depth with multiple linear regression analysis, or orthogonal text analysis [11, 12]. In the aspect of floor failure field management, Zhang et al. confirmed the coal floor failure conditions by monitoring the deformation degrees of the strata in various depths under the coal floor [13-17]. Liu et al. applied the electrical detection technology to detect water flowing fracture changing rules in coal floor strata during mining progress and established dynamic evolution geo-electric model of water flowing fractures when floor mining [18-20]. In terms of simulation test of goaf floor failure, Guo et al. detected the floor failure evolution progress through simulation tests system for the mining floor [21-23]. In the aspect of floor failure numerical simulation, Liu et al. studied floor

Jiazhen Li, I.jz2000@163.com | ${ }^{1}$ Mining Institute of Liaoning Technical University, Fuxin Liaoning 123000, China. 
failure deformation characteristics during mining through numerical simulation softwares [24-26].

The distribution law and failure characteristics of floor stress after mining inclined coal seam are different from those of the horizontal coal seam. With the change of the coal seam's inclination, the normal stress perpendicular to the floor decreases, while the shear stress parallels to the floor increases, increasing the amplitude and intensity of the floor rock movement. However, the above results are mostly limited to the horizontal coal seam, and the research on inclined coal seam is relatively few, and the influence of tectonic stress is not considered in theoretical calculation. Therefore, it is necessary to study the characteristics of mining-induced deformation and failure of the floor in goaf of the inclined coal seam to provide the theoretical basis for floor confined water prevention, floor roadway valid location, gas prevention, and mining adjacent coal seam. Based on coal seam goaf as the research object, using the fracture mechanics theory, simplifying the post-harvest space to bidirectional compression II inclined crack, through the crack tip stress field, combined with Mohr-Coulomb criterion, floor damage depth is derived to solve the equation.

\section{Solving model of floor stress in inclined coal seam goaf}

Because the working face dip length is much longer than the mining width, the effect of mining height is ignored [27]. Within the limits of the mining face, because the variation of lateral pressure around the coal seam is small, the variation of gradient lateral pressure on both sides of the coal seam is ignored. With the advance of the working face, the goaf is gradually closed. After that, normal stress on goaf will not produce stress singularity. Type I stress intensity factor $K_{1}=0$, goaf stress state can be purely regarded as type II shearing crack. According to inclined coal mining characteristics, mined areas are simplified as bi-directional compression inclined crack, as shown in Fig. 1. Working face length in Fig. 1 is $L_{\text {; }}$ under the combined action of vertical and lateral pressure, coal seam dip angle is $a$. Set up a rectangular coordinate system on floor strata and make $x$-axis parallel to strata direction and $y$-axis coincide with strata perpendicular.

According to the coordinate transformation of stress distribution, the stress state in goaf is shown as

$\left\{\begin{array}{l}\sigma_{x x}^{\infty}=\sigma \cdot \sin ^{2} \alpha+\lambda \sigma \cdot \cos ^{2} \alpha \\ \sigma_{y y}^{\infty}=\sigma \cdot \cos ^{2} \alpha+\lambda \sigma \cdot \sin ^{2} \alpha \\ \tau_{x y}^{\infty}=(1-\lambda) \sigma \cdot \sin \alpha \cdot \cos \alpha\end{array}\right.$

In these equations, $\sigma_{x x^{\prime}}^{\infty} \sigma_{y y^{\prime}}^{\infty} \tau_{x y}^{\infty}$ is the far-field stress/MPa; $\sigma$ is the vertical stress/MPa; $\lambda$ is the coefficient of horizontal pressure; $\alpha$ is the coal seam dip angle $/{ }^{\circ}$.

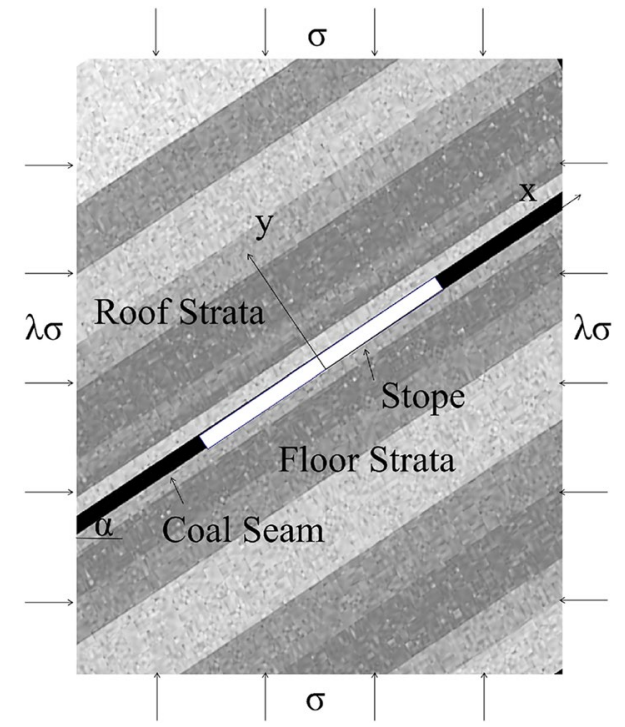

Fig. 1 Mechanical model of inclined coal seam floor

Positive stress $\sigma_{N}$ and shearing stress $\tau_{N}$ on goal are shown as

$\left\{\begin{array}{l}\sigma_{N}=\sigma_{y y}^{\infty}=\sigma \cdot \cos ^{2} \alpha+\lambda \sigma \cdot \sin ^{2} \alpha \\ \tau_{N}=\tau_{x y}^{\infty}=(1-\lambda) \sigma \cdot \sin \alpha \cdot \cos \alpha\end{array}\right.$

Thus, stress intensity factor on goaf tip is shown as

$K_{\|}=\tau_{\mathrm{N}} \sqrt{\frac{\pi L}{2}}=[(1-\lambda) \sigma \cdot \sin \alpha \cdot \cos \alpha] \sqrt{\frac{\pi L}{2}}$

Near-field stress state on goal tip is shown as

$\left\{\begin{array}{l}\sigma_{x x}^{c}=-\frac{K_{\|}}{\sqrt{2 \pi r}} \sin \left(\frac{\theta}{2}\right)\left[2+\cos \left(\frac{\theta}{2}\right) \cdot \cos \left(\frac{3 \theta}{2}\right)\right] \\ \sigma_{y y}^{c}=\frac{K_{\|}}{\sqrt{2 \pi r}} \cos \left(\frac{\theta}{2}\right) \cdot \sin \left(\frac{\theta}{2}\right) \cdot \cos \left(\frac{3 \theta}{2}\right) \\ \tau_{x y}^{c}=\frac{K_{\|}}{\sqrt{2 \pi r}} \cos \left(\frac{\theta}{2}\right)\left[1-\sin \left(\frac{\theta}{2}\right) \cdot \sin \left(\frac{3 \theta}{2}\right)\right]\end{array}\right.$

In these equations, $\sigma_{x x^{\prime}}^{c} \sigma_{y y^{\prime}}^{c} \tau_{x y}^{c}$ is the near-field stress/MPa; $r$ is the distance from stope tip $/ \mathrm{m} ; \theta$ is the included angle between $r$ and floor level ${ }^{\circ}$.

According to the principle stress calculating equation in elastic mechanics, the principle stress is shown as

$\left\{\begin{array}{l}\sigma_{1}=\frac{K_{\|}}{\sqrt{2 \pi r}}\left[-\sin \left(\frac{\theta}{2}\right)+\sqrt{1-\left(\frac{3}{4}\right) \sin ^{2} \theta}\right] \\ \sigma_{3}=\frac{K_{\|}}{\sqrt{2 \pi r}}\left[-\sin \left(\frac{\theta}{2}\right)-\sqrt{1-\left(\frac{3}{4}\right) \sin ^{2} \theta}\right]\end{array}\right.$ 
Substitute the principle stress into the Mohr-Coulomb criterion, as shown in equation

$\sigma_{1}-[(1+\sin \phi) /(1-\sin \phi)] \sigma_{3}=(2 c \cdot \cos \phi) /(1-\sin \phi)$

According to Eq. (6), the failure range of goaf edge can be obtained
In these equations, $\theta^{\prime}$ is the maximum failure angle of floor.

\section{Engineering application}

Take the working face 41,501 of HUAFENG Mine of the XINWEN Mining Industry as an example [28]. It focuses

$r^{\prime}=\frac{L \gamma^{2} H^{2}}{64 c^{2}}\left[\frac{(1-\lambda) \sin 2 \alpha}{\cos \phi /(1-\sin \phi)}\right]^{2}\left[\left(\frac{1+\sin \phi}{1-\sin \phi}-1\right) \sin \frac{\theta}{2}+\left(\frac{1+\sin \phi}{1-\sin \phi}+1\right) \sqrt{1-\frac{3}{4} \sin ^{2} \theta}\right]^{2}$

In these equations, $r^{\prime}$ is the yield damage radius $/ \mathrm{m} . ~ \gamma$ is the average bulk density of the overlying strata $/ \mathrm{kN} / \mathrm{m}^{-3}$. $H$ is the mining depth/m. $C$ is the floor cohesion/MPa. $\varphi$ is the internal frictional angle of floor $/{ }^{\circ}$.

The damaging range is shown in Fig. 2. Set lower part of the inclined coal goaf as polar origin, use dimensionless $r / r_{0}$ to stand for yielding damage radium $r$ and then $r_{0}$ is the yield size when $\theta=0$.There appears asymmetry in the layout of plastic failure zones in the inclined coal floor.

The maximum failure depth $h=r \times \sin \theta^{\prime}$ is shown as on No.15 coal seam with dip angle $30^{\circ}$, maximum depth $475 \mathrm{~m}$, minable thickness $2 \mathrm{~m}$, working face strike length $800 \mathrm{~m}$ and working face length $100 \mathrm{~m}$. Its direct floor is made of medium sandstone, about $6 \mathrm{~m}$ thick. Its hard floor is made of fine sandstone about $15 \mathrm{~m}$. Solve floor failure depth with an average modulus method. The average modulus method takes elasticity modulus as the main parameter to calculate each floor's average thickness hi' and transforms sliced floors into homogeneity-like floors. Solve contrastive analysis between homogeneity-like floor

$h=\frac{L \gamma^{2} H^{2}}{64 c^{2}}\left[\frac{(1-\lambda) \sin 2 \alpha}{\cos \phi /(1-\sin \phi)}\right]^{2}\left[\left(\frac{1+\sin \phi}{1-\sin \phi}-1\right) \sin \frac{\theta}{2}+\left(\frac{1+\sin \phi}{1-\sin \phi}+1\right) \sqrt{1-\frac{3}{4} \sin ^{2} \theta}\right]^{2} \sin \theta^{\prime}$

The distance between the floor maximum failure depth and working face $I=r \times \cos \theta^{\prime}$ is shown as failure depth and the original floor thickness to calculate the practical floor failure depth inversely.

$I=\frac{L \gamma^{2} H^{2}}{64 c^{2}}\left[\frac{(1-\lambda) \sin 2 \alpha}{\cos \phi /(1-\sin \phi)}\right]^{2}\left[\left(\frac{1+\sin \phi}{1-\sin \phi}-1\right) \sin \frac{\theta}{2}+\left(\frac{1+\sin \phi}{1-\sin \phi}+1\right) \sqrt{1-\frac{3}{4} \sin ^{2} \theta}\right]^{2} \cos \theta^{\prime}$

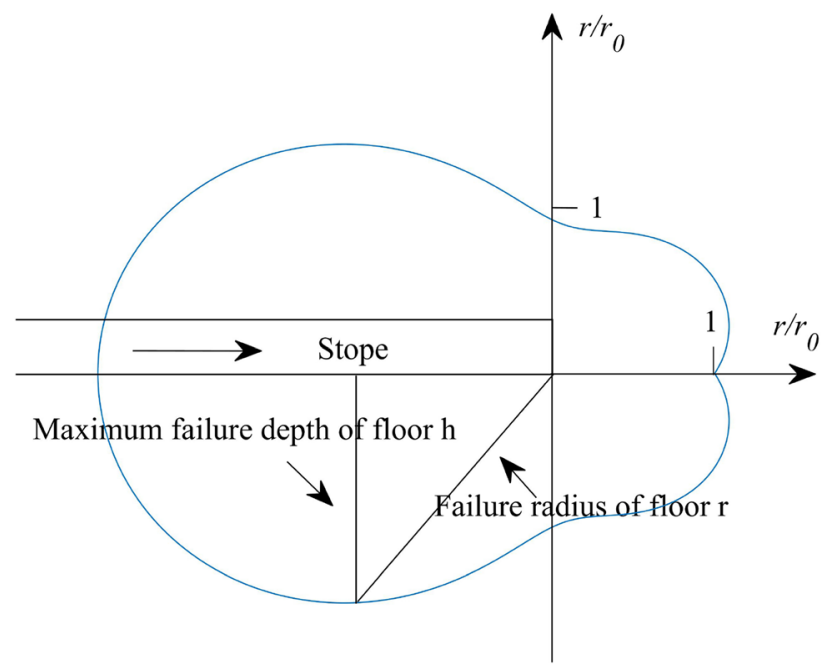

Fig. 2 Failure range in inclined mining stope tip

$$
\begin{aligned}
& h_{i}^{\prime}=h_{i} \sqrt{\frac{E_{i}}{E_{w}}} \\
& E_{w}=\sum_{1}^{n} h_{i} E_{i} / \sum_{1}^{n} h_{i}
\end{aligned}
$$

In Eqs. (10) and (11), $h_{\mathrm{i}}{ }^{\prime}$ is the equivalent strata thickness of No. i floor $/ \mathrm{m} ; E_{\mathrm{w}}$ is the elastic modulus weighted average/GPa; $h_{\mathrm{i}}$ is the original floor strata thickness of No. i floor $/ \mathrm{m}$; $E_{\mathrm{i}}$ is the floor elastic modulus/GPa.

We can figure out the floor strata average elastic modulus with the weighted average, which is $8 \mathrm{GPa}$. Similarly, the average cohesion force $c_{\mathrm{w}}$ is $4.7 \mathrm{MPa}$, and the average inner fictional angle $\varphi_{\mathrm{w}}$ is $32.7^{\circ}$. Working face 41,501 -floor strata equivalent thickness is shown in Table 1.

Take the parameters $L=100 \mathrm{~m}$, overlying strata average unit weight $\gamma=27 \mathrm{kN} \mathrm{m}^{-3}$, lower buried depth $H=475 \mathrm{~m}$, 
$c_{w}=4.7 \mathrm{MPa}, \varphi_{w}=32.7^{\circ}, \lambda=1.5$ [29] into Eq. (7). Use MAT$L A B$ to figure out equivalent failure depth in the lower part of goaf floor, which is $14.94 \mathrm{~m}$, and the equivalent failure depth of fine sandstone is $9.34 \mathrm{~m}$. Use Eq. (10) to reversely figure out the practical failure depth of the fine sandstone, which is $9.12 \mathrm{~m}$. Then, the practical floor failure depth is $15.12 \mathrm{~m}$, which basically matches the field-measured failure depth $15.49 \mathrm{~m}$ [28].

\section{Analysis of the influential factors from inclined coal seam goaf floor failure}

Based on Eq. (7), the inclined coal seam's yield failure zone size is influenced by factors such as working face length, mining depth, coal seam dip, coefficient of horizontal pressure, floor cohesion and internal frictional angle of the floor.

Take the parameters of the HUAFENG coal mine as an example. When other parameters remain the same, maximum floor failure depth varies with the change of coal seam dip angle, as shown in Fig. 3. With enlarging the dip angle, failure depth firstly increases and then begins to decrease. When the dip angle is $45^{\circ}$, failure depth reaches its peak value.

With the lateral pressure coefficient enlarging, failure depth firstly decrease and then begins to increases. When the floor tip is under hydrostatic pressure, the damage degree is low, as shown in Fig. 4.

When the internal frictional angle enlarges, the yielding range widens, and failure depth increases, as shown in Fig. 5.

As shown in Fig. 6, the working face length and mining depth positively correlate with the failure range; the floor cohesion is reversely proportional to the failure range.

Table 1 Working face floor equivalent thickness and other parameters

\begin{tabular}{llllll}
\hline $\begin{array}{l}\text { Floor } \\
\text { strata }\end{array}$ & $\begin{array}{l}\text { Elas- } \\
\text { ticity } \\
\text { modu- } \\
\text { lus/GPa }\end{array}$ & $\begin{array}{l}\text { Original } \\
\text { thickness/m }\end{array}$ & $\begin{array}{l}\text { Equivalent } \\
\text { thickness/m }\end{array}$ & $\begin{array}{l}\text { Cohe- } \\
\text { sion/ } \\
\mathrm{MPa}\end{array}$ & $\begin{array}{l}\text { Friction/ } \\
\left(^{\circ}\right)\end{array}$ \\
\hline $\begin{array}{c}\text { Middle } \\
\text { sand- } \\
\text { stone }\end{array}$ & 6.96 & 6 & 5.6 & 5.2 & 32 \\
$\begin{array}{c}\text { Fine } \\
\text { sand- } \\
\text { stone }\end{array}$ & 8.4 & 15 & 15.4 & 4.5 & 33 \\
\hline
\end{tabular}

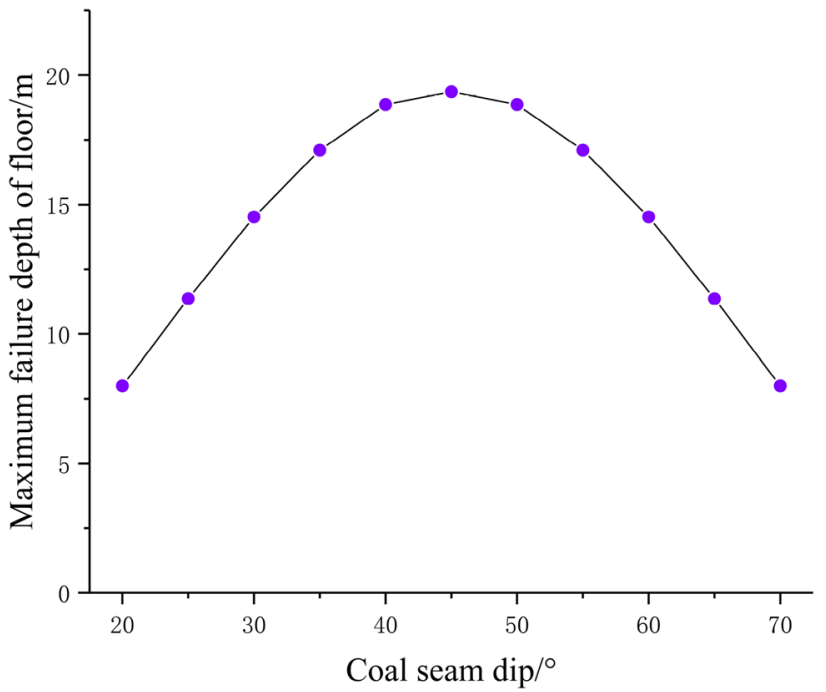

Fig. 3 Influence of the coal seam dip angle on floor failure depth

\section{Summary and conclusion}

(1) Based on the fracture mechanics, establish an inclined floor stress solution model. According to the twoway compressed stress field of the goaf end and the Mohr-Coulomb criterion, derive the solution equation for the floor failure depth of inclined coal seam; the equation rationality is verified through examples.

(2) The theoretical analysis of the floor failure characteristics shows that the plastic failure zones of inclined coal floor appear asymmetric distribution. Failure range and depth in-floor plastic zone gradually

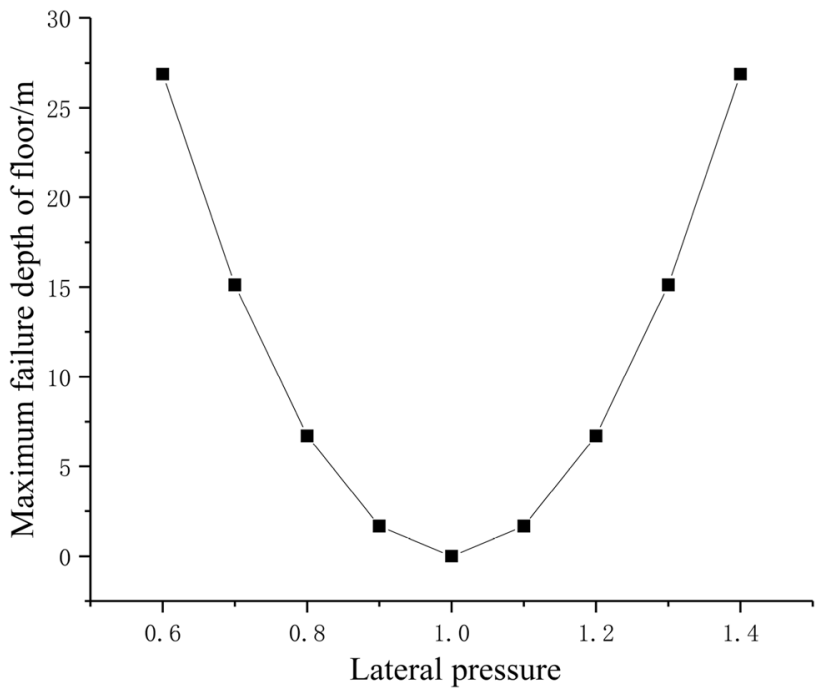

Fig. 4 Influence of the lateral pressure on floor failure depth 


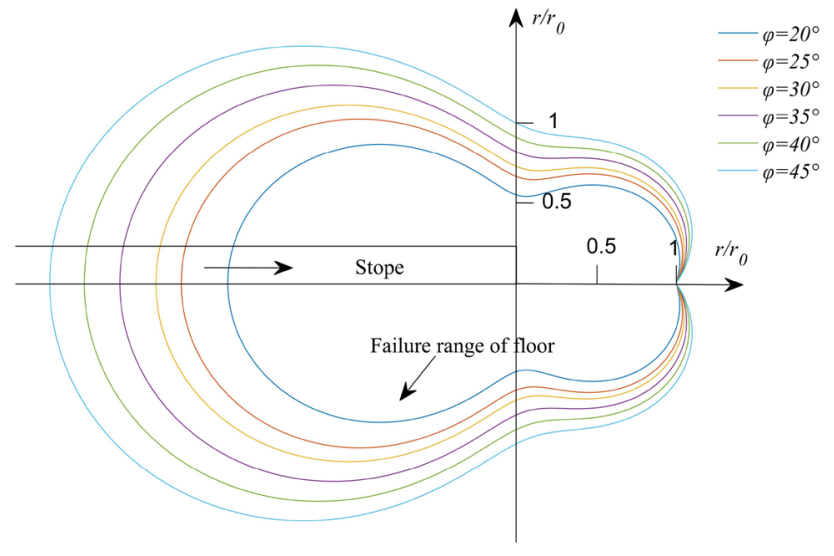

Fig.5 Influence of internal frictional angle on floor failure depth

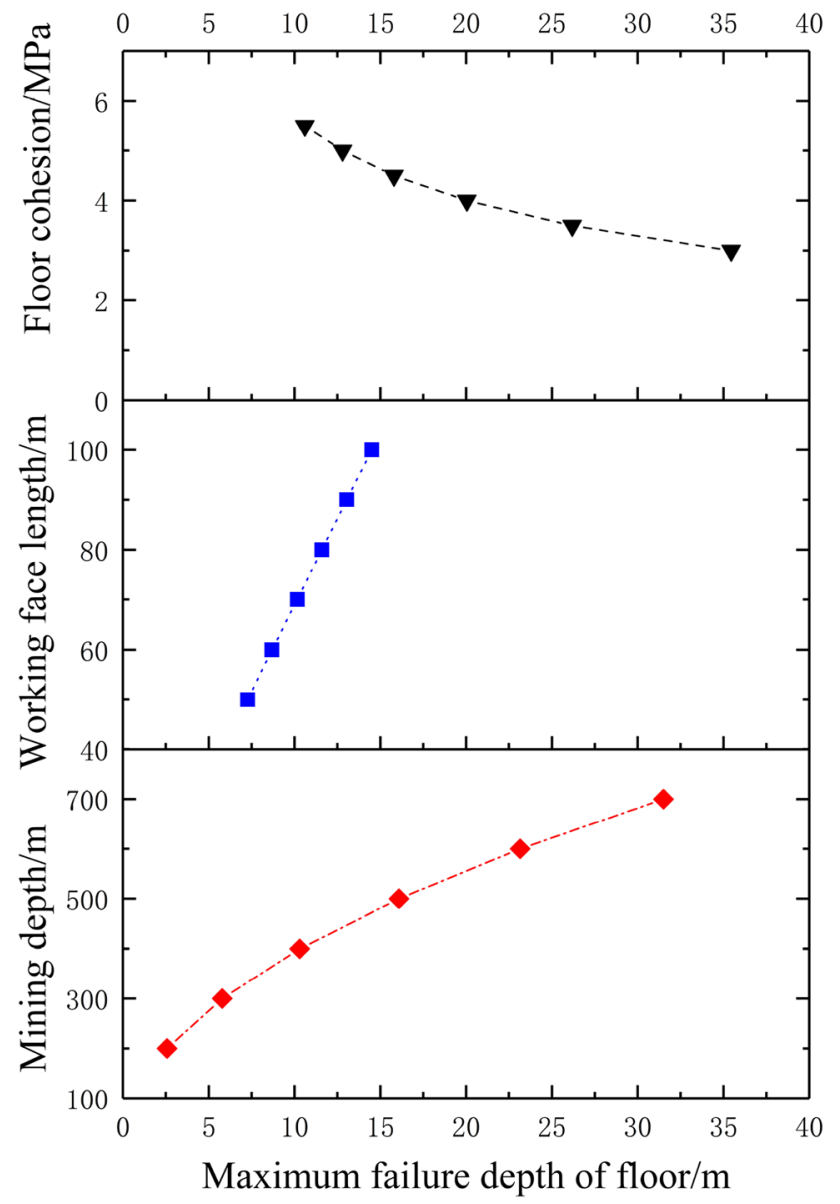

Fig. 6 Influence of the mining depth, working face length and floor cohesion on floor failure depth

enlarge when the coal face advances. The maximum failure depth of the floor position lies in the part of the lower goaf.

(3) Use the failure depth equation to analyze the floor failure factors. The inclined coal seam floor's failure zone size is influenced by factors such as working face length, mining depth, coal seam dip, coefficient of horizontal pressure, floor cohesion, and internal frictional angle of the floor.

Funding This study was funded by National Natural Science of China (Grant Number 51704148).

\section{Compliance with ethical standards}

Conflict of Interest The authors declare that they have no conflict of interest.

\section{References}

1. Zhu S, Lu L, Wu Y et al (2017) Comprehensive study on the deformation and failure characteristics of a mining-impacted deep double-longwall working face floor. J Geophys Eng 14(3):641653. https://doi.org/10.1088/1742-2140/aa64aa

2. Wen Z, Qu G, Wen J et al (2014) Deformation failure characteristics of coal body and mining induced stress evolution law. Sci World J, 1-8. https://doi.org/10.1155/2014/714507

3. $\mathrm{Xu} A B$, Gao F, Cheng HM et al (2011) Research on distribution and evolution law of the damage-fracture field in mining process. Adv Mater Res 243-249:5964-5967. https://doi. org/10.4028/www.scientific.net/AMR.243-249.5964

4. Huang Q, Cheng J (2017) Analytical model of stress field and failure depth in multilayered rock masses of mining floor based on the transfer matrix method. Geotech Geol Eng 35(6):1-8. https ://doi.org/10.1007/s10706-017-0277-x

5. Lu H, Meng X, Yan W et al (2020) Circular sliding solution for mining stability and failure depth of the layered structure of floor in coal face. Rock Soil Mech 01:1-9. https://doi.org/10.16285 /j.rsm.2018.2102

6. Su P, Wei Z (2018) Depth of floor failure of stope with mediumthickness coal seam. Geotech Geol Eng 36:1341-1347. https:// doi.org/10.1007/s10706-017-0396-4

7. Zhang J (2005) Investigations of water inrushes from aquifers under coal seams. Int J Rock Mech Mining Sci 42:350-360. https ://doi.org/10.1016/j.ijrmms.2004.11.010

8. Shi L, Xu D, Qiu M (2013) Improved on the formula about the depth of damaged floor in working area. J China Coal Soc 38(S2):299-303. https://doi.org/10.13225/j.cnki.jccs.2013.s2.029

9. Wang Z, Zhao W, Hu X (2019) Analysis of prediction model of failure depth of mine floor based on fuzzy neural network. Geotech Geol Eng 37:71-76. https://doi.org/10.1007/s10706-018-0591-y

10. Nemicik JA, Indraratna B, Gale W (2000) Floor Failure analysis at a longwall mining face based on the multiple sliding block mode. Geotech Geol Eng 18(3):175-192. https://doi. org/10.1023/a:1026533611345

11. Zhang F, Shen B (2019) Failure characteristics analysis of deep coal seam floor. J Mining Safety Eng 36(01):44-50. https://doi. org/10.13545/j.cnki.jmse.2019.01.007

12. Yin $\mathrm{H}$, Lefticariu L, Wei J et al (2016) A multi-method approach for estimating the failure depth of coal seam floor in a longwall coal mine in China. Geotech Geol Eng 34(5):1267-1281. https ://doi.org/10.1007/s10706-016-0006-x 
13. Zhang R, Jiang Z, Li X (2013) Study on the failure depth of thick seam floor in deep mining. J China Coal Soc 38(01):67-72. https ://doi.org/10.13225/j.cnki.jccs.2013.01.024

14. Cathy ML, Louis MM, Jefferey G et al (2002) The effects of sulfate on the physical and chemical properties of actively treated acid mine drainage floc. Mine Water Environ 21:114-120. https://doi. org/10.1007/s102300200032

15. Wang JA, Park HD (2003) Coal mining above a confined aquifer. Int J Rock Mech Mining Sci 40(4):537-551. https://doi. org/10.1016/S1365-1609(03)00029-7

16. Zhu S, Jiang Z, Cao D et al (2013) Restriction function of lithology and its composite structure to deformation and failure of mining coal seam floor. Nat Hazards 68(2):483-495. https://doi. org/10.1007/s11069-013-0623-0

17. Zhu S, Jiang Z, Zhou K et al (2014) The characteristics of deformation and failure of coal seam floor due to mining in XINMI coal field in China. Bull Eng Geol Environ 73(4):1151-1163. https ://doi.org/10.1007/s10064-014-0612-x

18. Liu S, Liu X, Jiang Z et al (2009) Research on electrical prediction for evaluating water conducting fracture zones in coal seam floor. Chin J Rock Mech Eng 28(02):348-356. https://doi. org/10.3321/j.issn:1000-6915.2009.02.019

19. Zhao GM, Meng XR (2011) Research on automatic detection technology for coal seam floor failure features. Key Eng Mater 467-469:1870-1875. https://doi.org/10.4028/www.scientific .net/KEM.467-469.1870

20. Su B, Yue J (2017) Research of the electrical anisotropic characteristics of water-conducting fractured zones in coal seams. Appl Geophys 14(2):216-224. https://doi.org/10.1007/s1177 0-017-0620-2

21. Guo W, Zhang S, Sun W et al (2018) Experimental and analysis research on water inrush catastrophe mode from coal seam floor in deep mining. J China Coal Soc 43(1):219-227. https:// doi.org/10.13225/j.cnki.jccs.2017.0774

22. Liu S, Liu W, Shen J (2017) Stress evolution law and failure characteristics of mining floor rock mass above confined water.
KSCE J Civil Eng 21:2665-2672. https://doi.org/10.1007/s1220 5-017-1578-6

23. Zhang B,Guo W, Zhang X et al (2016) Development and application of analogue testing system for floor confined water rise in coal mining. J China Coal Soc 41(08):2057-2062. https://doi. org/10.13225/j.cnki.jccs.2015.1500

24. Liu W, Wang D, Mu D (2017) Failure characteristics of coal seam floor in deep confined water. J Liaoning Tech Univ (Natural Science) 36(09):920-926. https://doi.org/10.11956/j.i ssn.1008-0562.2017.09.005

25. Zhu D, Tu S (2017) Mechanisms of support failure induced by repeated mining under gobs created by two-seam room mining and prevention measures. Eng Failure Anal 82:161-178. https:// doi.org/10.1016/j.engfailanal.2017.08.029

26. Zhu D, Song X, Li H, Liu Z, Huo Y (2019) Cooperative load-bearing characteristics of a pillar group and a gob pile in partially caved areas at shallow depth. Energy Sci Eng, 1-15. https://doi. org/10.1002/ese3.511

27. Li S, He T, Yi X (2018) Rock fracture mechanics. Science Press, Beijing

28. Song W, Liang Z (2020) Investigation on failure characteristics and water inrush risk of inclined floor mining above confined aquifer. Rock Soil Mech (02):1-11. https://doi.org/10.16285 /j.rsm.2019.0581

29. Kang H, Lin J, Zhang X (2007) Research and application of insitu stress measurement in deep mines. Chin J Rock Mech Eng 05:929-933. https://doi.org/10.1016/S1872-2067(07)60020-5

Publisher's Note Springer Nature remains neutral with regard to jurisdictional claims in published maps and institutional affiliations. 